\title{
AJIS EDITORIAL
}

AJIS publishes high quality contributions to theory and practice in the global Information Systems discipline. While research is global, AJIS contributions should have an emphasis on the Australasian context of the work. The journal welcomes papers on research and conceptual development based in a very wide range of inquiry methods, ways of thinking and modes of expression. Over half of the submissions to AJIS in the last 6 months were declined as they do not explicitly contribute to the development of the discipline. AJIS is an academic journal and submissions need to make scholarly and/or research contribution.

The Australasian Heads and Professors of Information Systems (ACPHIS) holds an annual workshop to review IS Education and Research, and to discuss the state of the IS discipline (see http://www.acphis.org.au/). At its Adelaide meeting in August 2007 the scope of AJIS was discussed. In particular, whether there should be:

1. an 'AJIS Intern' section of the journal for papers from $\mathrm{PhD}$ and Masters students. These papers would meet the normal standards for publication but would make a more modest contribution to theory. The main advantage would be to help research candidates to start publishing. There are practical issues however around whether the section would be seen as second rate when in fact the contribution made may well be as significant as papers in the rest of the journal.

2. an IS education section.

3. an IS industry section.

The general response from ACPHIS members was that it may be better not to complicate the journal and that AJIS Featured Themes could absorb special cases. If you have any thoughts on these matters please contact the editor.

Discussions about AJIS continued at 18th Australasian Conference on Information Systems at the University of Southern Queensland (see http://www.acis2007.usq.edu.au/) among members of the Australian Association for Information Systems (AAIS see http://www.aaisnet.org/). AAIS is the owner of AJIS. Resulting from those discussions a number of Associate Editors have been appointed whose task it is to see a paper through the reviewing process. This additional resource should speed up the process and will allow for more personal advice on the development of papers. Thanks to Julie Fisher, Jon Heales, John Gammack and David Wilson who are working on submissions.

All back issues of AJIS were loaded into the online system progressively over the first 6 months of 2007. By the end of the year there had been over 140,000 downloads of AJIS papers (just Google AJIS). Yes, 140,000. This exceeded the editorial board's expectations by orders of magnitude.

My thanks to Julie Fisher for her work in editing the Featured Theme and to the paper authors. Thanks also to John Campbell and Jon Heales for editorial help, and to the Faculty of Information Sciences and Engineering, University of Canberra, for its significant ongoing support and, in particular, Marina Materne.

Craig McDonald

craig.mcdonald@canberra.edu.au

December 2007 